\title{
A New Spectrophotometric Method for the Determination of Eflornithine Hydrochloride in Parenteral Formulation
}

\author{
Amit Kumar', Vijender Singh², Praveen Kumar,"* \\ ${ }^{1}$ Department of Pharmaceutical analysis, NKBR College of Pharmacy \& Research Centre, Meerut, India \\ ${ }^{2}$ Department of Pharmaceutical analysis, BBS Institute of Pharmaceutical \& Allied Sciences, Greater Noida, India \\ ${ }^{3}$ Department of Pharmaceutical Chemistry, S. D. College of Pharmacy and Vocational Studies, Muzaffarnagar, India \\ *Corresponding author: praveensha77@gmail.com
}

\section{Received February 04, 2013; Revised April 05, 2013; Accepted April 14, 2013}

\begin{abstract}
This work describes the development, validation and stable studies of a new, simple and reliable UV spectroscopy procedure for the analysis of eflornithine hydrochloride. A new rapid, precise, accurate, specific and simple UV Spectrophotometric analytical method was validated to assay eflornithine hydrochloride (DFMO) in parenteral. Measurements were taken at $\lambda \max 283$ using ethanol as the solvent. Beer's law is obeyed in the concentration ranges $4-32 \mu \mathrm{g} \mathrm{mL}^{-1}$ with a correlation coefficient (r) equal to 1 . The values of limit of detection (LOD) were $0.0675 \mu \mathrm{g} \mathrm{mL}^{-1}$ and limit of quantification (LOQ) were $0.2045 \mu \mathrm{g} \mathrm{mL}^{-1}$ for DFMO respectively. The value of molar absorptivity and sandell's sensitivity was $0.3918 \times 104 \mathrm{~L} \mathrm{~mol}^{-1} \mathrm{~cm}^{-1}$ and $0.1633 \mu \mathrm{g} \mathrm{cm}^{-2}$ respectively. The developed method was validated as per International Conference of Harmonization guidelines with respect to specificity, linearity, limit of detection, limit of quantification, accuracy, precision and robustness. The accuracy of the method was $100.23 \%$. The precision demonstrated a relative standard deviation of less than $1 \%$. The results were satisfactory when compared with the literature. The proposed method might be applied in routine quality control in the pharmaceutical industries since it is precise, accurate, simple and economic. Commercial formulation and laboratory prepared mixtures were successfully analyzed using the developed methods.
\end{abstract}

Keywords: Eflornithine Hydrochloride, UV-Spectrophotometric, pharmaceutical preparation, validation

\section{Introduction}

Eflornithine hydrochloride (DL-alpha-Difluoromethylornithine; DFMO) has the IUPAC name 2,5-diamino-2-(difluoromethyl) pentanoic acid [1,2]. Anhydrous eflornithine hydrochloride has molecular formula $\mathrm{C}_{6} \mathrm{H}_{12} \mathrm{~F}_{2} \mathrm{~N}_{2} \mathrm{O}_{2} \cdot \mathrm{HCl}$ (Figure 1) and a molecular weight of 218.65 [3].

Eflornithine is a specific, irreversible inhibitor of the enzyme ornithine decarboxylase, one of the key enzymes in the polyamine biosynthetic pathway [4,5]. The drug was originally developed for use in cancer, and is in phase III clinical trials for its use in preventing recurrence of superficial bladder cancer. It has been used as antiprotozoal agent in the treatment of meningoencephalic stage of trypanosomiasis caused by Trypanosoma brucei gambienze (African trypanosomiasis) [6,7]. It is now licensed for use in sleeping sickness in the FDA, US, FDA, Europe and twelve African countries [8]. Eflornithine (difluoromethylornithine, DFMO) has recently been approved for the treatment of Trypanosoma brucei gambiense trypanosomiasis [9].

A number of analytical methods have been reported for measuring DFMO in biological fluids and tissue extracts. These methods involved HPLC techniques $[10,11,12]$. The HPLC techniques currently available for the quantification of DFMO in biological fluids involve either pre or post column derivatization with UV or fluorescence detection $[13,14]$ and LC carried out by evaporative light scattering detection [15]. Few methods have been reported in the literature for the analysis of DFMO including spectrophotometry $[16,17]$.

The proposed method for eflornithine hydrochloride determination has many advantages over other analytical methods due to its rapidity, lower cost and environmental safety. Unlike the gas chromatographic and HPLC procedures, the instrument is simple and is not costly. All statistical values (percentage recoveries, RSD, confidence limits of the slope and intercept, LOD and LOQ) were within the acceptable limits. Economically, all the analytical reagents are inexpensive and available in any analytical laboratory.<smiles>NCCCC(N)(C(=O)O)C(F)F</smiles>

Figure 1. Molecular Structure of Eflornithine hydrochloride (DFMO)

The proposed method reports a new method for the determination of DFMO in parenteral pharmaceutical. The 
aim of this investigation was to develop a new, sensitive, cost effective and validated method for the determination of DFMO in pure form and in parenterals by spectrophotometry.

\section{Materials and Methods}

\subsection{Materials}

Eflornithine hydrochloride and $200 \mathrm{mg}$ vials (Ornidyl ${ }^{\circledR}$ ) were gifts from Wintac Limited, Bangalore (India). All reagents applied as solvents were analytical grade and obtained from Sigma-Aldrich (USA). Solvent utilized throughout the project was $95 \%$ ethanol. Water was always distilled.

\subsection{Instrumetation}

The equipments used were the following: A model Shimadzu UV-1601 with a fixed slit width of $2 \mathrm{~nm}$ using a pair of $1 \mathrm{~cm}$ matched quartz cells recording double beam UV- visible spectrophotometer connected to a computer loaded with Shimadzu UVPC; Mettler H51 analytical balance (Zürich, Switzerland).

\subsection{Spectrophotometric Measurements}

\subsubsection{Preparation of Solutions}

\subsubsection{Stock and Working Standard Solutions}

A stock solution of $1.0 \mathrm{mg} \mathrm{mL}^{-1}$ was prepared by dissolving $100 \mathrm{mg}$ of DFMO in a $100 \mathrm{~mL}$ of ethanol. Working standard solutions of DFMO of $100 \mu \mathrm{g} \mathrm{mL}^{-1}$ were prepared by appropriate dilution of the stock solution with ethanol. This solution was prepared daily.

\subsubsection{Sample Solutions}

Twenty vials of (Ornidyl 200 $\mathrm{mg} \mathrm{mL}^{-1}$ ) were used. The sample vial (SVP) containing $200 \mathrm{mg} \mathrm{mL}^{-1}$. Pipetted out $1 \mathrm{ml}$ and diluted to $100 \mathrm{ml}$ with ethanol. Now further dilutions were done with ethanol to get the final concentration of $100 \mu \mathrm{g} \mathrm{mL}^{-1}$. Appropriate dilutions were made using the same diluent.

\subsubsection{Determination of Absorption Maxima (lambda max) of Eflornithine (DFMO)}

$2.0 \mathrm{~mL}$ aliquot of standard DFMO solution of $10 \mu \mathrm{g} \mathrm{mL}^{-1}$ was pipetted into a $10 \mathrm{~mL}$ volumetric flask. The volume was made up to $10 \mathrm{~mL}$ with ethanol and solution was then scanned in the range of 200 to $400 \mathrm{~nm}$ against the reagent blank. The absorbance values are recorded and graphically represented in (Figure 2). On scanning the absorption maxima of (DFMO) $20 \mu \mathrm{g} \mathrm{mL}^{-1}$ was found out to be 283 $\mathrm{nm}$.

\subsubsection{Procedure for Standard Curve}

Aliquots of $0.4 \mathrm{~mL}, 0.8 \mathrm{~mL}, 1.2 \mathrm{~mL}, 1.6 \mathrm{~mL}, 2.0 \mathrm{~mL}$, $2.4 \mathrm{~mL}, 2.8 \mathrm{~mL}$ and $3.2 \mathrm{~mL}$ of $100 \mu \mathrm{g} \mathrm{mL}^{-1}$ solution of DFMO was pipetted into each of $10 \mathrm{~mL}$ volumetric flasks. The volume was made up to $10 \mathrm{~mL}$ with ethanol. The absorbance of solution was measured at $283 \mathrm{~nm}$ against ethanol as blank. The Zero-order absorption spectra and
Calibration curve for DFMO was shown respectively in (Figure 3 and Figure 4)

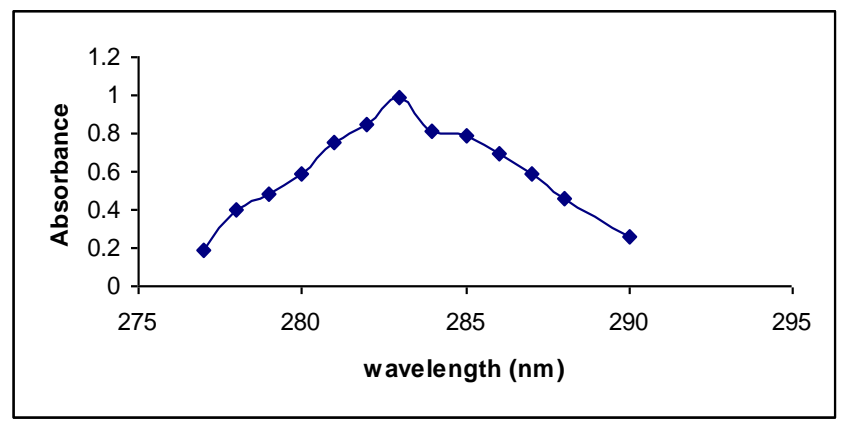

Figure 2. Absorption spectra of DFMO $\left(20 \mu \mathrm{gL}^{-1}\right)$

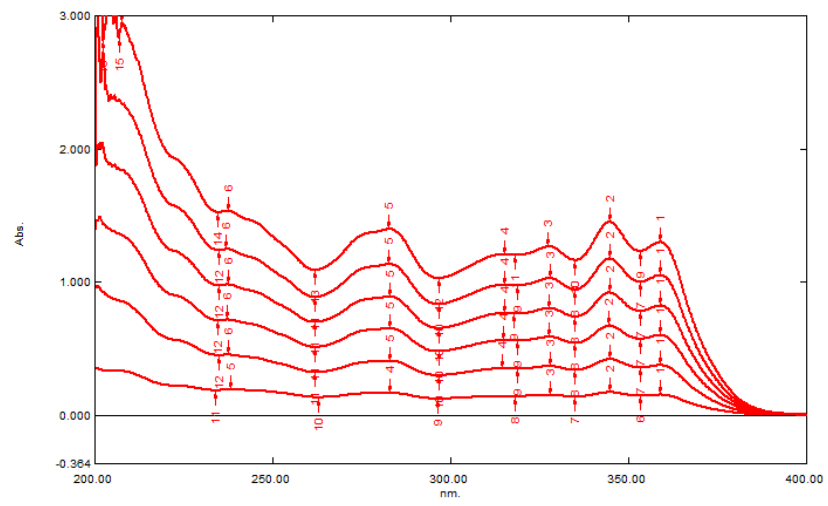

Figure 3. Zero-order absorption spectra for DFMO, showing $\lambda$ max at $283 \mathrm{~nm}$

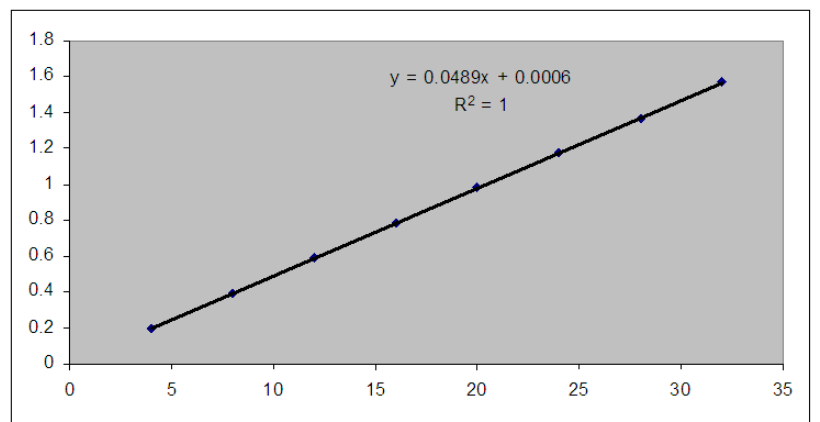

Figure 4. Calibration curve of DFMO at $283 \mathrm{~nm}$

\subsubsection{Method Validation}

The analytical method was validated according the International Conference for Harmonization (ICH) guidelines [18] under the optimized experimental conditions: linearity, accuracy, precision, specificity.

\subsubsection{Linearity}

The linearity was evaluated by linear regression analysis, which was calculated by the least squares regression method.

\subsubsection{The Limit of Detection (LOD) and Quantification (LOQ)}

The limit of detection was calculated by $\mathrm{LOD}=3.3 \sigma / \mathrm{S}$, where $\sigma$ is the standard deviation of the response of the blank or the standard deviation of intercepts of regression lines and $S$ is the slope of the calibration curve. The limit 
of quantification was calculated by $\mathrm{LOQ}=10 \sigma / \mathrm{S}$ under the ICH guidelines [18]

\subsubsection{Precision and Accuracy}

In order to assess the intra and inter-day precision and accuracy of the assay, were prepared as described above. The inter-day precision and accuracy were determined by analyzing the three level samples on 3 different days. Precision was expressed as the relative standard deviation (RSD \%). Accuracy was expressed as the mean relative error (RME \%).

\subsubsection{Recovery}

The recovery method was performed by adding known amounts of the studied compounds to a known concentration of the commercial pharmaceutical parenteral (standard addition method).

\section{Result and Discussion}

\subsection{Linearity and Range}

The proposed method showed good linearity in the concentration range of $4-32 \mu \mathrm{g} \mathrm{mL} \mathrm{m}^{-1}$. For DFMO method, the regression equation was $\mathrm{A}=0.0489 \mathrm{C}+0.0006$ with $\mathrm{r}=1$ (Figure 4). Analytical parameter for the determination of eflornithine hydrochloride was shown (Table 1).

Table 1. Analytical Parameters for the Determination of DFMO Using the Proposed Method ${ }^{\text {a) }}$

\begin{tabular}{|c|c|}
\hline Parameter & DFMO \\
\hline$\lambda$ max $(\mathrm{nm})$ & 283 \\
\hline Beer's Law Limit $\left(\mu \mathrm{g} \mathrm{mL}^{-1}\right)$ & $4-32$ \\
\hline Linear regression equation $\mathrm{A}=\mathrm{mC}+\mathrm{b}$ & 0.0489 \\
\hline Slope $(\mathrm{m})$ & 0.0006 \\
\hline Intercept $(\mathrm{b})$ & 1 \\
\hline Correlation coefficient $(\mathrm{r})$ & $0.3918 \times 10^{4}$ \\
\hline Malar absorptivity $\left(\mathrm{LmoL}^{-1} \mathrm{~cm}^{-1}\right)$ & 0.1633 \\
\hline Sandell's sensitivity $\left(\mu \mathrm{gm}^{-2}\right)$ & 0.0675 \\
\hline LOD $\left(\mu \mathrm{g} \mathrm{mL}^{-1}\right)$ & 0.2045 \\
\hline LOQ $\left(\mu \mathrm{g} \mathrm{mL} \mathrm{mL}^{-1}\right)$ & \\
\hline
\end{tabular}

a) $n=6$ (Average of six readings)

\subsection{Accuracy and Precision}

Accuracy and precision was determined from DFMO sample at three different concentrations in the calibration range in six replicates. The relative standard deviation (RSD) on the absorbance from three replicates solutions was found to be between 0.11 and $0.65 \%$. The data is summarized in (Table 2).

Table 2. Intra-day and Inter-day Precision Accuracy of DFMO Proposed Method ${ }^{\text {a) }}$

\begin{tabular}{|ccccc|}
\hline Method & $\begin{array}{c}\text { Added } \\
\text { concentration } \\
\left(\mu \mathrm{g} \mathrm{mL}^{-1}\right)\end{array}$ & $\begin{array}{c}\text { Found } \\
\text { concentration } \\
\left(\mu \mathrm{g} \mathrm{mL}^{-1}\right)\end{array}$ & $\begin{array}{c}\text { RME } \\
(\%)\end{array}$ & $\begin{array}{c}\text { RDS } \\
(\%)\end{array}$ \\
\hline Intra-day & 4 & 4.04 & 1 & 0.42 \\
& 10 & 10.05 & 0.5 & 0.35 \\
& 22 & 22.03 & 0.14 & 0.28 \\
Inter-day & 32 & 32.02 & 0.06 & 0.11 \\
& 4 & 4.10 & 2.5 & 0.65 \\
& 10 & 10.09 & 0.90 & 0.45 \\
& 22 & 22.11 & 0.50 & 0.32 \\
& 32 & 32.08 & 0.25 & 0.21 \\
\hline
\end{tabular}

a) $n=4$ (Average of four readings)

\subsection{Recovery Study of Proposed Method}

The recoveries of the standard addition method (Table 3) suggested that high accuracy of the proposed methods. The study was performed by increasing standard addition of known amounts of studied drugs to an unknown concentration (constant volume) of the standard drug. Known concentration DFMO was taken which is dissolved in ethanol and the volume make with ethanol. A constant volume of the unknown solutions was added to each of eight $10 \mathrm{ml}$ volumetric flasks. Then a series of increasing volumes of working standard solutions were added. Finally, each flask was made up to the mark with ethanol for DFMO and mixed well. The concentration of the working standard solutions added should be chosen to increase the concentration of the unknown by minimum $50 \%$ in each succeeding flask. The resulting mixtures were analyzed and recoveries were found to be between $\%$ 99.08 and 100.23 .

Table 3. Result of Recovery Studies by Standard Addition Method ${ }^{\text {a) }}$

\begin{tabular}{|cc|}
\hline Added concentration $\left(\mu \mathrm{g} \mathrm{mL}^{-1}\right)$ & Recovery \pm RSD \% \\
\hline 4 & $100 \pm 0.42$ \\
8 & $99.08 \pm 0.21$ \\
12 & $99.15 \pm 0.27$ \\
16 & $100.02 \pm 0.65$ \\
20 & $100.03 \pm 0.12$ \\
24 & $99.12 \pm 0.14$ \\
28 & $99.11 \pm 0.15$ \\
32 & $100.23 \pm 0.71$ \\
\hline
\end{tabular}

a) $n=4$ (Average of four readings)

\subsection{Ruggedness (Reproducibility)}

The ruggedness of the method was determined by carrying out the experiment by three different analysts. The average value of \% RSD of the findings for determination of DFMO was found to be 1.014. This showed that the method was reproducible by three different analysts (Table 4).

Table 4. Reproducibility of the method by three different analysts

\begin{tabular}{|cccc|}
\hline Method & \multicolumn{3}{c|}{$\begin{array}{c}\left(\mu \mathrm{g} \mathrm{mL}^{-1}\right) \\
\end{array}$} \\
\hline & Actual & Obtained & \%RSD \\
\hline Analyst 1 & 12 & 12.16 & \\
Analyst 2 & 12 & 11.86 & 0.85 \\
Analyst 3 & 12 & 11.97 & \\
\hline Analyst 1 & 18 & 18.66 & \\
Analyst 2 & 18 & 18.41 & 0.63 \\
Analyst 3 & 18 & 18.50 & \\
\hline Analyst 1 & 24 & 24.64 & \\
Analyst 2 & 24 & 24.13 & \\
Analyst 3 & 24 & 24.25 & \\
\hline
\end{tabular}

a) $n=4$ (Average of four readings)

\subsection{The Limit of Detection (LOD) and Quantification (LOQ)}

Calibration curve was repeated for 6 times and the standard deviation (SD) of the intercepts was calculated.

Then LOD and LOQ were measured as follows

$\mathrm{LOD}=3.3 \times \mathrm{SD} /$ slope of calibration curve

$\mathrm{LOQ}=10 \times \mathrm{SD} /$ slope of calibration curve

$\mathrm{SD}=$ Standard deviation of intercepts

The values of LOD and LOQ are given in Table 1. 


\subsection{Assay of Commercial Formulation}

Applicability of the method was tested by analyzing the commercially available formulation as Ornidyl. The data is summarized in (Table 5) was found to be very close to the label value of commercial pharmaceutical formulation, which showed that the method was applicable for determination of DFMO from their parenteral formulations.

Table 5. Analysis of Commercial Formulation

\begin{tabular}{|cccc|}
\hline Parenteral & $\begin{array}{c}\text { Label claimed } \\
(\mathrm{mg})\end{array}$ & $\begin{array}{c}\text { Concentration } \\
\text { found }(\mathrm{mg})\end{array}$ & $\begin{array}{c}\% \text { Recovery } \pm \\
\text { SD }\end{array}$ \\
\hline ORNIDYL & 200 & $\mathbf{2 0 0 . 1 9 5}$ & $\mathbf{1 0 0 . 1 0} \pm 1.6$ \\
\hline
\end{tabular}

\section{Conclusion}

Selective solvent extraction method was suitable technique for the reliable analysis of parenteral commercial formulations as Ornidyl. The validated analytical method for quantitative determination of eflornithine hydrochloride in parenteral has the advantages of simplicity, speed, sensitivity, low cost conditions and a lack of polluting reagents. All validation parameters were found to be highly satisfactory, including linearity, accuracy, precision, selectivity, robustness and adequate detection and quantitation limits. The validated method is a good alternative for routine quality control of eflornithine hydrochloride by the pharmaceutical industry and quality control laboratories. This procedure uses simple reagents, requires minimal sample preparation and generates only a small amount of residue. Its use is therefore encouraged for routine analysis.

In contrast, the described method has many advantages: it does not need expensive apparatus; it is simple and quick. Its linear range is relatively wide. It has good selectivity. Furthermore, the proposed method may be successfully used to determine DFMO in pharmaceutical formulations. Accordingly, the method is practical and valuable.

\section{Acknowledgements}

First author is highly thankful to IFTM University, Moradabad, India for Ph.D. registration and facilities. We thank Mr. S.P.Venkatesh Prasad, PEC College of Pharmacy, Bangalore, India, for his technical support and Wintac Ltd, Bangalore, India, for providing a sample of DFMO as a gift.

\section{Abbreviations}
UV:
ultraviolet;
HPLC: high-pressure liquid chromatography.

\section{References}

[1] Clarkson, A. B. Jr., Bacchi, C. J., Mellow, G. H., Nathan, H. C., McCann, P. P. and Sjoerdsma, A, "Efficacy of combinations of difluoromethylornithine and bleomycin in a mouse model of central nervous system African trypanosomiasis," Proc. Natl. Acad. Sci., 80(18). 5729-5733. Sep. 1983.

[2] Available: https://www.chemindustry.com/chemicals/077763.html. [1999].

[3] Available: http://www.rxlist.com/vaniqa-drug.htm. [May 12, 2008].

[4] Balfour, J. A. and McClellan, K, "Topical eflornithine," Am. J. Clin. Dermatol, 2(3). 197-201. 2001.

[5] Goldberg, B., Rattendi, D., Yarlett, N., Lloyd, D. and Bacchi, C. J, "Effects of carboxylmethylation and polyamine synthesis inhibitors on methylation of Trypanosoma brucei cellular proteins and lipids," J. Eukaryot. Microbiol., 44. 352-8. 1997.

[6] Pepin, J., Guern, C., Milord, F. and Schechter, P. J, "Difluoromethylornithine for arseno-resistant trypanosoma brucei gambiense sleeping sickness," The Lancet, 330. 1431-1433. 1987.

[7] Merali, S. and Clarkson, A. B. Jr, "Polyamine content of Pneumocystis carinii and response to the ornithine decarboxylase inhibitor DL-alpha-difluoromethylornithine," Antimicrob. Agents Chemother., 40. 973-978. 1996.

[8] Available: http://www.accessdata.fda.gov/scripts/cder/drugsatfda/index.cfm?f useaction=Search.SearchAction\&SearchType=BasicSearch\&searc h Term=eflornithine\&Search_Button=Submit. [April 18, 1986].

[9] Milord, F., Loko, L., Ethier, L., Mpia, B. and Pépin, J, "Eflornithine concentrations in serum and cerebrospinal fluid of 63 patients treated for Trypanosoma brucei gambiense sleeping sickness,” Trans. R. Soc. Trop. Med. Hyg., 87(4). 473-7. Jul-Aug. 1993.

[10] Cohen, J. L., Ko, R. J., Lo, A. T., Shields, M. D. and Gilman, T. M, "High-pressure liquid chromatographic analysis of eflornithine in serum," J. Pharm. Sci., 78(2). 114-6. Feb. 1989.

[11] Huebert, N. D., Schwartz, J. J. and Haegele, K. D, "Analysis of 2difluoromethyl-DL-ornithine in human plasma, cerebrospinal fluid and urine by cation-exchange high-performance liquid chromatography,” J. Chromatogr. A., 762(1-2). 293-8. Feb. 1997.

[12] Saravanan, C., Kumudhavalli, M. V., Kumar, M. and Jayakar, B, "A new validated RP-HPLC method for estimation of eflornithine hydrochloride in tablet dosage form," J. Phar. Res., 2. 1730-1731. 2009.

[13] Kilkenny, M. L., Slavik, M., Christopher, M. R. and Stobaugh, J. F, "Plasma analysis of alpha-difluoromethylornithine using precolumn derivatization with naphthalene-2,3-dicarboxaldehyde/CN and multidimensional chromatography," J. Pharm. Biomed. Anal., 17. 1205-1213. 1998.

[14] Jansson-Löfmark, R., Römsing, S., Albers, E. and Ashton, M, "Determination of eflornithine enantiomers in plasma by precolumn derivatization with o-phthalaldehyde-N-acetyl-1cysteine and liquid chromatography with UV detection," Biomed. Chromatogr., 24(7). 768-773. July 2010.

[15] 15. Malm, M. and Bergqvist, Y, "Determination of eflornithine enantiomers in plasma, by solid-phase extraction and liquid chromatography with evaporative light-scattering detection," J. Chromatogr. B. Analyt. Technol. Biomed. Life Sci., 846. 98-104. 2007.

[16] Kumar, A., Venkatesh, Prasad, S. P., Mohan, S. and Kumar, P, "Spectrophotometric determination of eflornithine hydrochloride as active pharmaceutical ingredient using sodium 1,2naphthoquinone-4-sulfonate as the derivative chromogenic reagent," Trade Sci Inc., 7, 2008.

[17] Kumar, A., Venkatesh, Prasad, S. P., Mohan, S. and Singh, A. K, "Estimation of eflornithine hydrochloride by UV spectroscopy," Trade Sci. Inc., 8. 2009.

[18] Validation of Analytical Procedures, Methodology ICH Harmonised Tripartite Guideline, Having Reached Step 4 of the ICH Process at the ICH Steering Committee meeting on November 6, 1996. 